\title{
In-Plane Silicon-On-Nothing Nanometer-Scale Resonant Suspended Gate MOSFET for In-IC Integration Perspectives
}

Cédric Durand, Fabrice Casset, Philippe Renaux, Nicolas Abelé, Bernard Legrand, Denis Renaud, Eric Ollier, Pascal Ancey, Adrian M. Ionescu, Lionel Buchaillot

\section{To cite this version:}

Cédric Durand, Fabrice Casset, Philippe Renaux, Nicolas Abelé, Bernard Legrand, et al.. In-Plane Silicon-On-Nothing Nanometer-Scale Resonant Suspended Gate MOSFET for In-IC Integration Perspectives. IEEE Electron Device Letters, Institute of Electrical and Electronics Engineers, 2008, 29 (5), pp.494-496. cea-00320837

\section{HAL Id: cea-00320837 https://hal-cea.archives-ouvertes.fr/cea-00320837}

Submitted on 20 Sep 2008

HAL is a multi-disciplinary open access archive for the deposit and dissemination of scientific research documents, whether they are published or not. The documents may come from teaching and research institutions in France or abroad, or from public or private research centers.
L'archive ouverte pluridisciplinaire HAL, est destinée au dépôt et à la diffusion de documents scientifiques de niveau recherche, publiés ou non, émanant des établissements d'enseignement et de recherche français ou étrangers, des laboratoires publics ou privés. 


\title{
In-Plane Silicon-On-Nothing Nanometer-Scale Resonant Suspended Gate MOSFET for In-IC Integration Perspectives
}

\author{
C. Durand, F. Casset, P. Renaux, N. Abelé, B. Legrand, D. Renaud, \\ E. Ollier, P. Ancey, A. M. Ionescu, and L. Buchaillot
}

\begin{abstract}
A 14-MHz in-plane nanoelectromechanical resonator based on a resonant-suspended-gate (RSG) MOSFET principle and integrated in a front-end process is demonstrated. The devices are in-plane flexural vibration mode beams $(L=10 \mu \mathrm{m}$, $w=165 \mathrm{~nm}$, and $h=400 \mathrm{~nm}$ ) with $120-\mathrm{nm}$ gaps. This letter details the design and process flow fabrication steps. Then, the electrical device characteristics are demonstrated, comprising static and dynamic studies around the resonant frequency. Devices enable the comparison of a pure capacitive detection with the RSG-MOSFET-based detection on the same component, showing a 4.3-dB-huge peak. Due to its output signal amplification and in-IC integration potentialities, the RSG-MOSFET-based detection is ideal for any type of nanoelectromechanical structure displacement detection.
\end{abstract}

Index Terms - In-IC integration, in-plane resonator, nanometerscale resonator, resonant suspended gate (RSG) MOSFET, silicon on nothing (SON).

\section{INTRODUCTION}

$\mathbf{F}$ OR THE first time, an in-plane nanoelectromechanical (NEM) resonator based on a resonant suspended gate (RSG) MOSFET principle [1], [2] and integrated in a front-end process is demonstrated. Advanced silicon-on-nothing (SON) technology [3] based on industrial 8-in tools is used to fabricate RSG-MOSFETs with high in-IC integration capabilities.

This letter reports on the design, fabrication process, measurement setup, and experimental results of a $14-\mathrm{MHz}$ NEM resonator and compares a classic capacitive detection [4] with

Manuscript received December 31, 2007; revised February 8, 2008. The review of this letter was arranged by Editor K. De Meyer.

C. Durand is with the STMicroelectronics, 38926 Crolles, France, with the Institut d'Electronique de Microélectronique et de Nanotechnologie (IEMN), CNRS UMR 8520, 59652 Villeneuve d'Ascq, France, and also with the Commissariat à l' Énergie Atomique (CEA)/Laboratoire d'Électronique et Technologies de l'Information (LETI), Micro and Nanotechnology Innovation Centre (MINATEC), 38054 Grenoble, France (e-mail: cedric.durand@ st.com).

F. Casset, P. Renaux, D. Renaud, and E. Ollier are with the Commissariat à l' Énergie Atomique (CEA)/Laboratoire d'Électronique et Technologies de l'Information (LETI), Micro and Nanotechnology Innovation Centre (MINATEC), 38054 Grenoble, France.

N. Abelé and P. Ancey are with the STMicroelectronics, 38926 Crolles, France.

B. Legrand and L. Buchaillot are with the Institut d'Electronique de Microélectronique et de Nanotechnologie (IEMN), CNRS UMR 8520, 59652 Villeneuve d'Ascq, France.

A. M. Ionescu is with the Electronics Laboratory (LEG), École Polytechnique Fédérale de Lausanne (EPFL), 1015 Lausanne, Switzerland.

Color versions of one or more of the figures in this letter are available online at http://ieeexplore.iee.org.

Digital Object Identifier 10.1109/LED.2008.919781

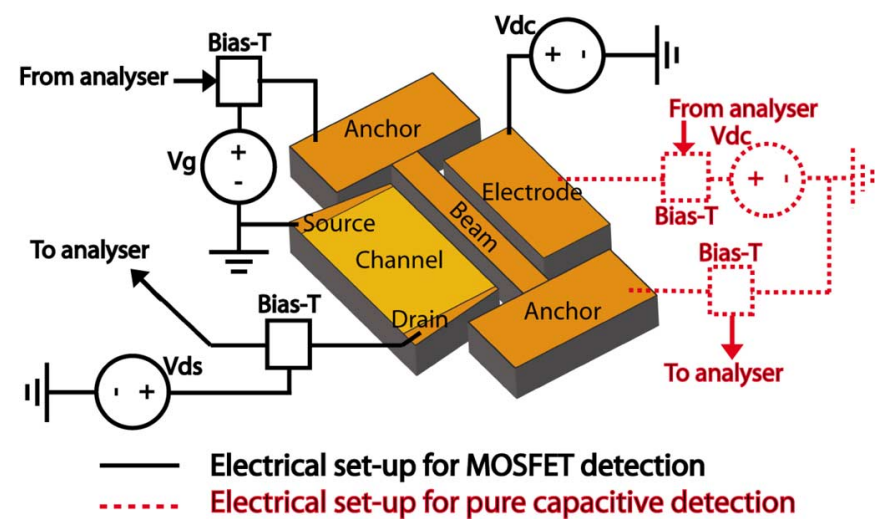

Fig. 1. Principle schematic and electrical characterization setup of the RSGMOSFET device.

a MOSFET-based detection. Operational dc and vibrating characteristics of laterally excited nanogap RSG-MOSFETs are also reported for the first time. The proposed process and fabricated resonators enable the in-IC integration of off-chip modules such as time reference functions with significant cost, size, and consumption reduction [5].

\section{DEVICE DESIGN AND FABRICATION}

The lateral MOSFET is composed of a vibrating gate and a channel separated from the mobile gate by an insulator and an air gap (Fig. 1). Drain and source are placed in the same horizontal plane as the gate. The mobile-gate (beam) vibration at resonance frequency modulates the mobile charges of the MOS conductive channel formed along the lateral etched sidewall and, consequently, the drain current. The design and the proposed process enable the integration of both capacitive [4] and amplified detections using the MOSFET intrinsic gain (tailored by the transistor transconductance $i_{\mathrm{ds}}=\nu_{\mathrm{gs}} \times g_{m}$ ).

Devices were fabricated by using the SON technology [3] to achieve sub-100-nm gaps and 400-nm-thick single-crystal silicon resonators using only front-end processes [4], [6] and materials, ensuring the in-IC integration capabilities. The fabrication-process flow presented in [4] and [6] is resumed in Fig. 2. It starts with the patterning of active areas through a thermal $\mathrm{SiO}_{2}$ layer. A SiGe sacrificial layer is then grown by selective epitaxy and followed by a low boron-doped $\left(10^{16} \mathrm{at} / \mathrm{cm}^{3}\right)$ nonselective single-crystal silicon epitaxy. Phosphorous dopants are implanted $\left(10^{19} \mathrm{at} / \mathrm{cm}^{3}\right)$ to define gate, 


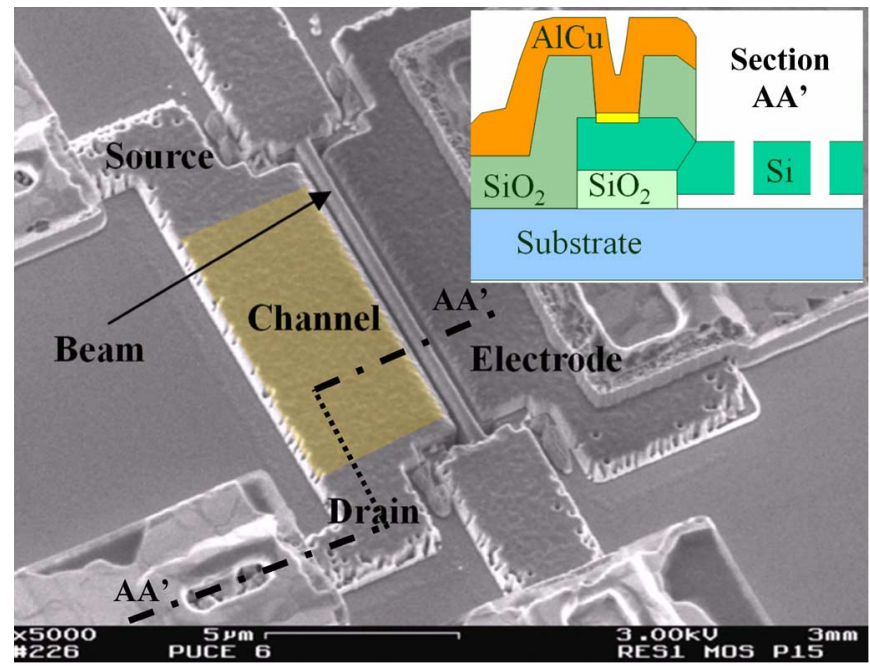

Fig. 2. Perspective SEM picture of a beam $(L=10 \mu \mathrm{m}, w=165 \mathrm{~nm}$, and $d=120 \mathrm{~nm}$ )

source, and drain. E-beam lithography is used to define gaps and the resonator structure, leading to a 47-nm gap resolution. The 400-nm-thick silicon structural layer is then etched by an anisotropic plasma to define air gaps. After dopant diffusion and activation annealing steps, structures are released by an isotropic plasma etch of the $\mathrm{SiGe}$ sacrificial layer. The released structures were protected by a nonconformal $\mathrm{SiO}_{2}$ deposition to allow metal pad deposition. Fig. 2 shows a picture of a suspended RSG-MOSFET.

\section{Measurement Setup}

RF characterizations are performed by using an Agilent 8753E network analyzer. Fig. 1 shows the two measurement configurations for comparing capacitive and MOSFET detections on the same device.

For a capacitive-detection measurement [4], the transmitted signal through the resonator is measured between the vibrating beam and the electrode of the device. A bias voltage $V_{\mathrm{dc}}$ is applied on the electrode; the beam and the substrate are grounded to avoid any pull-in effect of the structure.

For a MOSFET-detection measurement, three bias voltages are applied: the electrode $V_{\mathrm{dc}}$, the gate voltage $V_{g}$, and the drain voltage $V_{\mathrm{ds}}$. Optimal $V_{g}$ and $V_{\mathrm{ds}}$ values for dynamic characterization were extracted from the static MOSFET characteristics $I_{d}\left(V_{g}\right)$ shown in Fig. 3 as well as $I_{d}\left(V_{\mathrm{ds}}\right)$.

\section{EXPERIMENTAL RESULTS}

Fig. 3 shows the static electrical $I_{d}\left(V_{g}\right)$ measured characteristics of the MOSFET transistor. The threshold voltage $V_{\text {th }}$ is $2 \mathrm{~V}$. An OFF-state leakage current of $0.1-1.3 \mu \mathrm{A}$ depending quasi-linearly on $V_{\mathrm{ds}}$ is observable at $V_{g}=0 \mathrm{~V}$. It is attributed to a photolithography misalignment when protecting channel from phosphorous implants. Indeed, channel surface was partially implanted on a few nanometer widths, generating a 2.1-M $\Omega$ short-circuit resistor in parallel of the transistor, explaining the high leakage current and its quasi-linear dependence on $V_{\mathrm{ds}}$. Optimal operating points were defined from

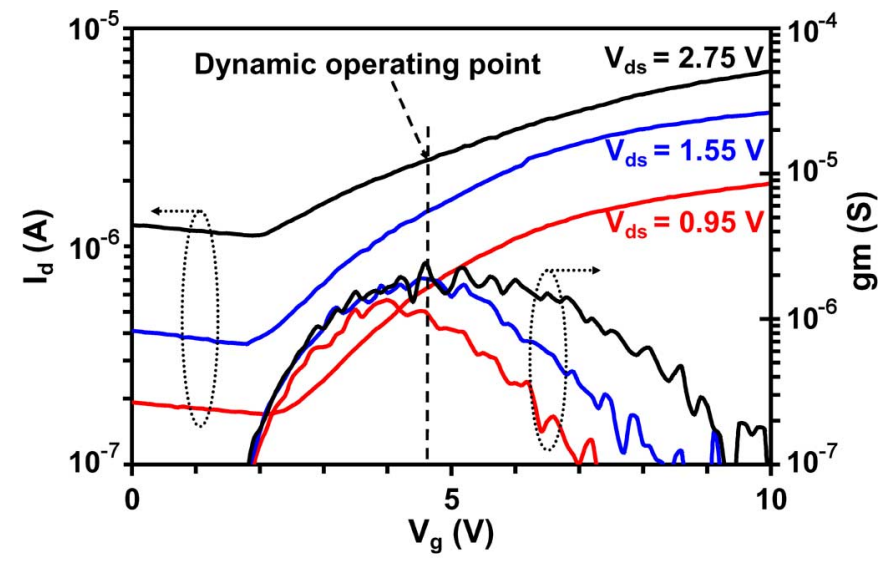

Fig. 3. Static MOS characteristics $I_{d}\left(V_{g}\right)$ and $G_{m}\left(V_{g}\right)$.

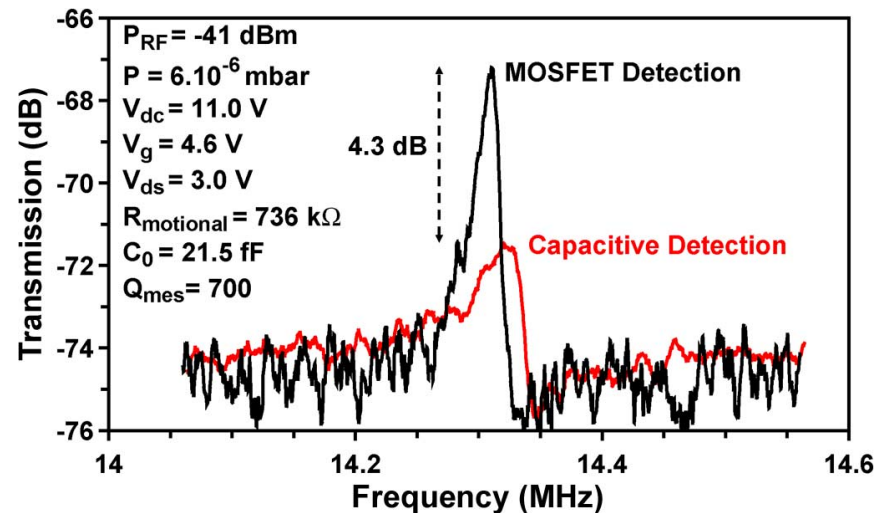

Fig. 4. Capacitive- and MOSFET-detection comparison on the dynamic response of the NEMS ( $L=10 \mu \mathrm{m}, w=165 \mathrm{~nm}$, and $d=120 \mathrm{~nm}$ ).

static characteristics: $V_{g}$ being $4.6 \mathrm{~V}$ corresponding to the maximum of transconductance and $V_{\mathrm{ds}}$ being $3 \mathrm{~V}$ corresponding to the saturation region, with an OFF-state leakage of $1.4 \mu \mathrm{A}$.

Fig. 4 compares the resonant amplitude response between capacitive and MOSFET detections, on the same structure ( $L=10 \mu \mathrm{m}, w=165 \mathrm{~nm}$, and $d=120 \mathrm{~nm})$. The fundamental resonance frequency was measured to be 14.33 and $14.31 \mathrm{MHz}$ with capacitive and MOS detections, respectively. The slight discrepancy between the two measurements is explained by the different bias conditions of actuation between the MOS and capacitive detections. The frequency shift is mainly due to the MOSFET channel surface potential which is set to zero in the case of the capacitive detection. Measurements are in good agreement with mechanical analytical calculations and FEM simulations, giving 14.43 and $14.42 \mathrm{MHz}$, respectively, being independent of the detection principle. The extracted motional resistance $R_{m}$ is $736 \mathrm{k} \Omega$, and the $C_{0}$ capacitance is $21.5 \mathrm{fF}$. The MOSFET detection yields a $+4.3 \mathrm{~dB}$ signal amplification compared with the capacitive detection due to the MOSFET intrinsic gain. This amplitude could be increased first by optimizing the transistor design (channel width/length ratio), hence enabling a higher $g_{m}$, and second by limiting the leakages. In this way, the SiGe layer has to be completely etched, and the $\mathrm{SiO}_{2}$ insulation layer has to be thicker. 


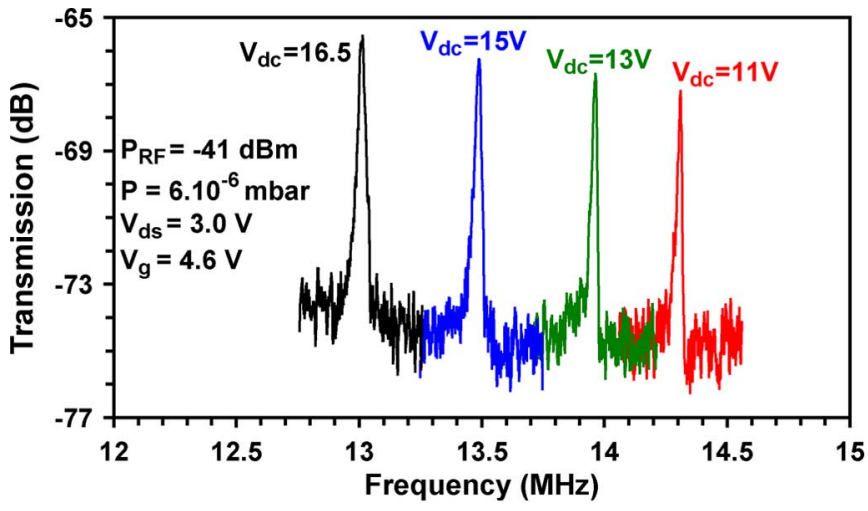

Fig. 5. Influence of $V_{\mathrm{dc}}$ variation on the dynamic response of the NEMS ( $L=10 \mu \mathrm{m}, w=165 \mathrm{~nm}$, and $d=120 \mathrm{~nm}$ ) using the MOSFET detection.

Fig. 5 shows the influence of the beam polarization on the output signal using the MOSFET detection. Its amplitude increases with $V_{\mathrm{dc}}$ due to the larger beam vibration amplitude caused by the larger electrostatic excitation. The effect is also reinforced by the air-gap reduction induced by the increase in $V_{\mathrm{dc}}$. On the other hand, the electrostatic field increases with $V_{\mathrm{dc}}$ and acts as a negative stiffness, shifting down the resonant frequency of $10 \%$ for a $5.5 \mathrm{~V} V_{\mathrm{dc}}$ variation. The influence of $V_{\mathrm{ds}}$ on the device response was also investigated. Results show an increase in the resonant peak amplitude with $V_{\mathrm{ds}}$, as predicted on static characteristics for a given $V_{g}$ of $4.6 \mathrm{~V}$, due to the increase in $g_{m}$ with $V_{\mathrm{ds}}$. Moreover, a $V_{\mathrm{ds}}$ variation from 2.0 to $3.5 \mathrm{~V}$ induces a $0.16 \%$ decrease in the resonant frequency. This effect is negligible regarding the shift induced by $V_{\mathrm{dc}}$.

Dependence of resonators' behavior with environmental conditions was studied in [4] on similar devices. Resonant frequencies shift down quasi-linearly with temperature (from $-50{ }^{\circ} \mathrm{C}$ to $100{ }^{\circ} \mathrm{C}$ ), giving a temperature coefficient of frequency of $-32 \mathrm{ppm} /{ }^{\circ} \mathrm{C}$. Quality factors were found to be maximum and constant at low pressure $(<1$ Torr), whereas they decrease at higher pressures, showing that even for nanoscaled beams, air damping remains the major source of dissipation.

\section{CONCLUSION}

We fabricated and experimentally demonstrated, for the first time, a fully operational in-plane 14-MHz RSG-MOSFET resonator with intrinsic tunable amplification. The unique large gain, in terms of peak detection amplitude, makes this new device ideal for any type of NEM structure displacement detection. Future works will focus on reliability issues such as fatigue [7], packaging, and in-IC integration for industrial perspectives.

\section{REFERENCES}

[1] N. Abelé, R. Fritschi, K. Boucart, F. Casset, P. Ancey, and A. M. Ionescu, "Suspended-gate MOSFET: Bringing new MEMS functionality into solidstate MOS transistor," in IEDM Tech. Dig., Washington, DC, Dec. 5-7, 2005, pp. 479-481.

[2] D. Grogg, D. Tsamados, N. D. Badila, and A. M. Ionescu, "Integration of MOSFET detection in MEMS resonators for improved output detection," in Proc. Transducers, Lyon, France, Jun. 10-14, 2007, pp. 1709-1712.

[3] S. Monfray, T. Skotnicki, Y. Morand, S. Descombes, M. Paoli, P. Ribot, A. Talbot, D. Dutartre, F. Leverd, Y. Le Friec, R. Pantel, M. Haond, D. Renaud, M.-E. Nier, C. Vizioz, D. Louis, and N. Buffet, "First $80 \mathrm{~nm}$ SON (Silicon-On-Nothing) MOSFETs with perfect morphology and high electrical performance," in IEDM Tech. Dig, Washington, DC, Dec. 3-5, 2001, pp. 2971-2974.

[4] C. Durand, F. Casset, B. Legrand, M. Faucher, P. Renaux, D. Mercier, D. Renaud, D. Dutartre, E. Ollier, P. Ancey, and L. Buchaillot, "Characterization of In-IC integrable in-plane nanometer scale resonators fabricated by a silicon on nothing advanced CMOS technology," in Proc. MEMS, Tucson, AZ, Jan. 13-17, 2008, pp. 1016-1019.

[5] C. T.-C. Nguyen, "Vibrating RF MEMS technology fuel for an integrated micromechanical circuit revolution?" in Proc. Transducers, Seoul, Korea, Jun. 5-9, 2005, pp. 243-246.

[6] C. Durand, F. Casset, P. Ancey, F. Judong, A. Talbot, R. Quenouillère, D. Renaud, S. Borel, B. Florin, and L. Buchaillot, "Silicon on nothing MEMS electromechanical resonator," in Proc. DTIP, Stresa, Italy, Apr. 25-27, 2007, pp. 326-331.

[7] A. George, A. Jacques, and M. Legros, "Low-cycle fatigue in silicon: Comparison with fcc metals," Fatigue Fract. Eng. Mater. Struct., vol. 30, no. 1, pp. 41-56, Jan. 2007. 